\title{
A Case-Control Study on Behavioral Addictions and Neurocognition: Description of the BANCO and BANCO2 Protocols
}

\author{
Elodie Hurel (1D) ${ }^{1,2}$ \\ Marie Grall-Bronnec ${ }^{1,2}$ \\ Elsa Thiabaud' \\ Anaïs Saillard' \\ Jean-Benoît Hardouin ${ }^{2}$ \\ Gaëlle Challet-Bouju' ${ }^{1,2}$ \\ 'CHU Nantes, Addictology and \\ Psychiatry Department, Nantes, France; \\ ${ }^{2}$ INSERM UI246 SPHERE (methodS in \\ Patient-centered outcomes \& HEalth \\ ResEarch), University of Nantes, \\ University of Tours, Nantes, France
}

Correspondence: Gaëlle Challet-Bouju Email gaelle.bouju@chu-nantes.fr

\begin{abstract}
Introduction: Only two behavioral addictions (BAs) are currently recognized in international classifications (gambling disorder: GbD; gaming disorder: GmD), while some of them await further investigation (food addiction: FA; sexual addiction: SA). Neurocognitive functioning is considered a risk factor for BAs. Research is quite abundant for $\mathrm{GbD}$ and highlights specific deficits in several cognitive functions. Nevertheless, grey areas still exist. The aim of this research programme is to investigate the neurocognitive profiles of patients presenting with various BAs and to establish parallels between different forms of BA to achieve a common addiction concept.
\end{abstract}

Methods and Analysis: This research program is composed of two studies sharing the same methodology but focusing on different samples: the BANCO study aims to include 30 individuals with a GbD, whereas the BANCO2 study aims to include 30 individuals with a GmD, 30 with a SA, and 30 with a FA. Moreover, for each BA group, 30 healthy controls will be recruited, matched by sex, age and education level. Several cognitive tasks will be completed by participants. Cue reactivity and physiological responses, as well as clinical data regarding addiction characteristics and personality, will also be investigated. A composite score based on the cognitive tasks will be computed using principal component analysis (PCA). Overall cognitive performance and detailed performance on the different cognitive tasks will be compared between individuals with BAs and their matched healthy controls using linear models with random effects. Comparisons will also be made between BA groups to investigate specific alterations associated with each disorder.

Discussion: The results of this research programme will impact both research and clinical areas by (i) providing new knowledge for discussions regarding the inclusion of BAs under the spectrum of addictive disorders; (ii) improving understanding of addiction mechanisms in general; (iii) providing clarity in the grey areas in neurocognitive research on BAs and improving the understanding of less studied BAs, (iv) guiding clinicians to propose therapeutic alternatives and complementary programmes.

Trial Registration: BANCO study (ClinicalTrials.gov NCT03202290); BANCO2 study (ClinicalTrials.gov NCT03967418).

Keywords: behavioral addiction, neurocognition, neuropsychology, gaming disorder, gambling disorder, sexual addiction, food addiction you hereby accept the Terms. Non-commercial uses of the work are permitted without any further permision from Dove Medical Press Limited, provided the work is properly attributed. For permission for commercial use of this work, please see paragraphs 4.2 and 5 of our Terms (https://www.dovepress.com/terms.php). 


\section{Introduction}

\section{Background and rationale} Behavioral Addictions

Behavioral addictions (BAs) are non-substance addictions. The object of addiction can, therefore, be a sport, food, sex, gambling, gaming, or any behavior that could produce pleasure and provide relief from internal discomfort that is employed in a pattern characterized by (i) recurrent failure to control the behavior (powerlessness) and (ii) continuation of the behavior despite significant negative consequences (unmanageability). ${ }^{1}$

Regarding the actual recognition of BAs, international manuals of mental diseases recognize only two of them. The first BA to be acknowledged was gambling disorder $(\mathrm{GbD})$ in the "Substance-related and addictive disorders" section of the fifth edition of the Diagnostic and Statistical Manual of Mental Disorders (DSM) in 2013. ${ }^{2}$ The classification in the tenth edition of the International Classification of Disease (ICD-10) went from an impulsecontrol disorder to an addictive behavior in the ICD-11 in 2018. The second BA, gaming disorder (GmD), was defined more recently in 2018 in the ICD-11. Other pathological behaviors are often reported as BAs in the literature, such as sexual addiction $(\mathrm{SA}){ }^{3}$ food addiction (FA), ${ }^{4,5}$ excessive exercise, ${ }^{6}$ kleptomania, $^{7}$ or shopping addiction. ${ }^{8}$ Recently, $\mathrm{SA}^{9,10}$ and $\mathrm{FA}^{4,11}$ have been under particular investigation regarding whether they should be considered BAs. However, the level of evidence is still too poor, and further research is needed.

Regarding SA in particular, the lack of evidence rather than contradictory pieces of evidence seems responsible for this lack of acknowledgement. ${ }^{12}$ The ICD-11 included "compulsive sexual behavior disorder", which has a prevalence rate of 2.0 to $3.7 \%$ in the general population $^{12}$, within the "Impulse-control disorder" section. This disorder is still awaiting further investigation regarding the mechanisms of its development and maintenance before it can be included in the addiction section. ${ }^{13}$ Symptoms presented in the ICD-11 include (i) sexual activities as the main interest, which leads to neglect in other spheres, (ii) recurrent failures to control or diminish sexual activities, (iii) continuation of the behavior despite negative consequences, (iv) persistence of the behavior even if there is no satisfaction from it, (v) persistence during a prolonged period of time and (vi) negative impacts in different spheres of daily functioning. ${ }^{13,14}$ There have been some arguments in the literature to consider SA in the framework of an addictive disorder rather than an impulse-control disorder. ${ }^{15}$ First, literature reviews of human studies have suggested that people with SA experience withdrawal symptoms (such as anxiety or depression), tolerance (increase in the behavior) and difficulties stopping the behavior. ${ }^{16,17}$ Second, similar to addictive symptoms, it has been shown that patients with unregulated use of pornography display higher selfreported cognitive impulsivity and higher levels of craving than recreational and frequent users of pornography ${ }^{18}$. Third, the exploration of patterns of cerebral activation during viewing of explicit sexual videos ${ }^{19}$ and during performing an incentive delay task with explicit sexual stimuli $^{20}$ showed increased striatal activation in a group of problematic users of pornography compared to controls, supporting the idea that sexual cues are more salient for problematic users of pornography. Taken together, neuroimaging studies of people with compulsive sexual behavior showed a similar pattern of activation to patients with addiction, specifically in networks implicated in cue reactivity. $^{21}$ Finally, even if international classifications have not yet classified compulsive sexual behavior disorder as an addiction, clinicians have already proposed some treatments recognized as effective in the field of addiction, such as cognitive behavioral therapy and motivational interviewing. ${ }^{22}$ Pharmacological treatments, such as naltrexone, which is known to inhibit dopamine release in the ventral part of the striatum and is used as a treatment to regulate craving in alcohol use disorder, have been used with patients with a compulsive sexual behavior disorder and resulted in improvements in their symptoms. ${ }^{22-24}$ These arguments are thus in favour of considering compulsive sexual behavior disorder as a BA, which could permit the expansion of alternative treatments and research, thereby providing benefit to patients. ${ }^{25}$

The concept of FA emerged during the previous century, but human research has primarily emerged in the last decade. ${ }^{5}$ This concept is based on the model of substance use disorder as proposed in the $\mathrm{DSM}^{2}$. Indeed, FA reflects the idea that food can be considered addictive and can trigger addictive behavior such as (i) ingestion of a larger amount of food than was intended, (ii) constant desire or repetitive failure to stop the behavior, (iii) recovery from or engagement in the behavior occupies much time, (iv) withdrawal from daily life spheres, and (v) repetition of the behavior despite negative consequences ${ }^{2,26-28}$. Its classification as a BA remains under discussion because the ingestion of food 
can be likened to the ingestion of substances, while the behavior of eating itself can be considered the BA. ${ }^{11,27,28}$ FA can be evaluated with the Yale Food Addiction Scale $\left(\right.$ YFAS $\left.^{29}\right)$, which is a 25 -item questionnaire that assesses eating habits within the last 12 months and is based on the DSM-5 criteria for substance use disorder. ${ }^{2}$ Using this questionnaire, research found a prevalence of FA ranging from $1.7 \%$ to $8.8 \%$ in non-clinical samples from European countries ${ }^{26}$. In clinical samples, the prevalence is higher and can reach up to $95.7 \%$ in patients diagnosed with binge eating disorder, ${ }^{30} 60 \%$ in patients with anorexia nervosa, $81.5 \%$ in patients with bulimia nervosa and $72.2 \%$ in patients with an eating disorder not otherwise specified. ${ }^{31}$ A systematic review of research in bulimia nervosa showed that FA plays a role in the maintenance of bulimia nervosa symptoms. ${ }^{32}$ Moreover, in bulimia nervosa, the lower the FA severity is, the better the shortterm prognosis after a brief psychoeducation group session. ${ }^{33}$ In summary, FA can be found in individuals with any eating disorder but still needs to be explored to determine whether it can be considered a diagnostic entity itself or a transdiagnostic symptom among eating disorders. $^{26,28}$ Regarding neuronal activity patterns, higher FA scores in a non-clinical sample were correlated with higher neuronal activation in the anterior cingulate cortex, medial orbitofrontal cortex and amygdala in anticipation of palatable food cues, suggesting a link between FA and motivational networks. ${ }^{34}$ To our knowledge, such an investigation has not been performed in clinical samples of patients with FA, but it seems that reward processing circuits are altered in patients with eating disorders. ${ }^{35}$ For example, obese individuals compared to controls display altered striatal dopamine functioning ${ }^{36,37}$ and higher activation of motivational networks when looking at high-calorie food. ${ }^{28,38}$ Additionally, patients with binge eating disorder or bulimia nervosa exhibited higher food cue reactivity than controls without an eating disorder ${ }^{39}$. Therefore, this body of evidence suggests alterations in the neuronal circuits involved in reward and motivational processes, as found in substance use disorder patients ${ }^{37}$. Furthermore, a review of the literature on animal studies exploring food addiction also supports the classification of FA as an addiction by showing neurobiological changes in rodents when exposed to high-fat or highly palatable food. ${ }^{40}$
Considering their shared characteristics with other BAs and substance use disorder, there are strong arguments, especially clinical arguments, that SA and FA could be considered BAs. ${ }^{41}$

\section{Cognitive Functioning in Addictions}

The Interaction of Person-Affect-Cognition-Execution (I-PACE) model $^{42,43}$ postulates that addiction is a multistep process. During the first step, external and internal triggers lead to affective or cognitive responses that guide the decision to realize the behavior to produce gratification or relief. The repetition of the behavior combined with individuals' characteristics progressively modifies the response to external and internal triggers, leading to the facilitation of craving and a loss of control over the behavior. Such changes are increased by deficits in cognitive control over stimuli related to problematic behaviors. The search for gratification gradually turns into the search for compensation, and biases in coping styles and cognition participate in the maintenance of problematic behaviors.

Thus, factors that influence the loss of control over urges are central to understanding the mechanisms underlying addictions and can be leveraged to achieve recovery in treatment approaches. Among those factors, cognitive functioning may play a central role in the loss of "willpower". ${ }^{44}$ Indeed, the triadic neurocognitive model of addiction ${ }^{45}$ postulates that the loss of control over addictive behaviors is the result of an imbalance between three key interacting cognitive systems. The impulsive system processes automatic functions dealing with routine situations and salient behaviors through the amygdalastriatum network. The reflective system handles decision making in new and more complex situations through two executive networks: (i) frontostriatal and frontoparietal networks deal with cool executive functions that handle basic executive functioning without an influence of emotions, while (ii) the ventromedial prefrontal cortex mediates hot executive functions that trigger emotional states based on memories and knowledge. Finally, the interoceptive system, which involves the insula, modulates the interplay between the first two systems. This system is in charge of translating physiological information into feelings, and therefore, it would be implicated in craving and urges $^{45}$. According to this model, addiction is the result of an imbalance in the interactions among the three systems. The reflective system would be hypo-activated, leading to impaired control and undervaluation of future consequences, while the impulsive system would be hyper- 
activated, triggering hyper-salience to addiction-related cues. Finally, the interoceptive system would allocate more resources to the hyper-activated impulsive system, thus favouring addiction-related cues, at the expense of the reflective system, leading to the loss of willpower. ${ }^{45,46}$

Research regarding cognitive functioning in patients presenting with a BA has mainly been developed in the field of GbD. Indeed, GbD patients were found to show impairments in risky decision making, ${ }^{47}$ especially in the context of uncertainty. ${ }^{48}$ Regarding inhibitory control, ie, the ability to stop an already programmed action, ${ }^{49}$ analysis of the literature highlighted deficits in a large panel of tasks such as the go-nogo task, stop-signal task (SST) and Stroop task. ${ }^{50,51}$ Regarding flexibility, ie, the ability to adapt behavior or a strategy in the face of a change in the environment, ${ }^{52}$ the results have not converged, and further study is required. ${ }^{53}$ A review of the literature showed that attentional processes also seem to be biased, with an attentional bias towards gambling cues highlighted in GbD patients. ${ }^{54}$ Additionally, some cognitive functions, such as social cognition (ie, all functions that permit the development and maintenance of relationships with others, from basic functions such as the detection of emotions to more complex ones such as the understanding of irony), ${ }^{5-57}$ are still underexplored, ${ }^{58,59}$ To our knowledge, only one study has explored social cognition in those with GbD and suggested specific alterations in nonverbal emotional processing. ${ }^{60}$ Overall, despite the growing literature exploring neurocognition in those with $\mathrm{GbD}$, further research is still needed. ${ }^{48}$

Regarding $\mathrm{GmD}$, the analysis of the literature has also shown deficits in several tasks (go-nogo, Stroop, and SST) assessing inhibitory control. ${ }^{61}$ More specifically, GmD patients seem to display the same pattern of performance on an SST task as patients with an alcohol use disorder. ${ }^{62}$ Regarding decision-making abilities, $\mathrm{GmD}$ patients also seem to choose riskier options ${ }^{63-65}$ and have a preference for immediate rewards rather than later rewards. ${ }^{64}$ Nevertheless, studies assessing decision making under uncertainty have obtained mixed results, and more research is needed. ${ }^{64}$ Attentional bias towards videogame-related stimuli has also been highlighted in a group of players with an addiction to massively multiplayer online role-playing games (MMORPGs) compared to non-addicted players and non-players. ${ }^{66}$ Regarding social cognition, only three studies have been conducted in $\mathrm{GmD}$ to our knowledge, and these studies suggested deficits in specific pre-attentional emotional face processing ${ }^{67,68}$ as well as specific patterns in social decision making ${ }^{69}$. Therefore, individuals with $\mathrm{GmD}$ seem to display patterns of neurocognitive functioning quite similar to those observed in individuals with GbD. Nevertheless, further research is needed to confirm these similarities and to characterize potential specific alterations.

Regarding FA, the research on neurocognition is less developed and inconsistent. One study showed, for example, that obese women with FA displayed worse performance than obese women without FA when assessing decision making in a situation of uncertainty and sustained attention. ${ }^{70}$ Nevertheless, these findings were not replicated when comparing patients with binge eating disorder and FA or patients with only FA to control patients with obesity and no $\mathrm{FA}^{71}$, showing that further research is needed to characterize the neurocognitive functioning of patients with FA. Additionally, executive functioning was linked to (i) weight loss in groups of patients with obesity ${ }^{72,73}$ and (ii) the presence of binge eating disorder, ${ }^{74}$ showing the importance of cognition in the treatment of patients presenting with eating disorders, among whom there is a high prevalence of FA. ${ }^{75}$

Finally, a review of studies examining cognition in patients with SA was recently published ${ }^{76}$. For example, one study found that these patients displayed enhanced attentional bias towards explicit cues in a visual dot-probe task. ${ }^{77}$ Moreover, one study conducted with patients with compulsive sexual behavior showed a deficit in inhibitory control when they were compared to controls in a go-nogo task, ${ }^{78}$ while the examination of executive functioning of hypersexual men compared to controls showed no deficits. ${ }^{79}$ Finally, it was found in a group of users of internet pornography that participants with the lowest inhibitory control abilities in self-report and behavioral tasks displayed a higher score on a scale assessing addiction severity. $^{80}$ Additionally, the tendency for cybersex addiction has been linked to executive function difficulties in a multitasking task in a non-clinical sample. ${ }^{81}$ These studies suggested the presence of neurocognitive alterations in SA samples, but further and more extensive research is still needed. In summary, the study of the neurocognitive profile of patients seeking treatment for BAs is still in its infancy, especially for certain disorders and cognitive functions. 
Objectives of the BANCO and BANCO2 Protocols

Research on $\mathrm{GbD}, \mathrm{GmD}$, FA and SA has provided several clinical arguments suggesting that these disorders be brought closer to the concept of addictions. However, the neurocognitive characteristics associated with these disorders are still understudied, especially for SA and FA and for less investigated aspects of neurocognition (social cognition or flexibility, for example). This literature gap may explain why the connections of BAs to the general concept of addiction is still the subject of debate and why certain disorders, clinically close to addictions, are not currently recognized as such. Indeed, to our knowledge, no research has been conducted involving several BAs, exploring a large panel of cognitive functions, and linking observations to clinical profiles. This type of research would permit (i) an exploration of potential common neurocognitive patterns among $\mathrm{GbD}, \mathrm{GmD}, \mathrm{FA}$ and $\mathrm{SA}$ in a transversal neurocognitive investigation of the concept of BA and (ii) an exploration of the specificities of each of them. Moreover, the exploration of BAs has the advantage of allowing the investigation of the neurocognitive characteristics of addictions without the neurotoxic effects linked to the ingestion of substances. Increasing knowledge in this field would thus provide a better understanding of addiction in general.

Thus, the main objective of the BANCO and BANCO2 studies is to investigate the neurocognitive profiles of patients with BAs and to compare them with matched healthy controls (HCs). The BANCO study involves $\mathrm{GbD}$ patients and their matched controls, while the BANCO2 study involves $\mathrm{GmD}, \mathrm{SA}$ and FA patients and their matched controls. A secondary objective of these protocols is to compare each addiction with each other (including those investigated in separate studies) to (i) explore potential common neurocognitive patterns across BAs and (ii) identify specific characteristics linked to each BA. The global objective is to enhance the understanding of the general phenomenon of addiction by obtaining a precise profile of each addiction.

Finally, the last objective is to link neurocognitive observations to clinical profiles.

\section{Trial Design}

The two studies share the same methodology with a crosssectional case-control design allowing comparison of several groups of patients with BAs with matched control groups (ie, participants without any history of a BA) on several neurocognitive tasks.

\section{Method and Analysis}

This study protocol was registered on ClinicalTrials.gov with the identification NCT03202290 for the BANCO study and NCT03967418 for the BANCO2 protocol. The studies began in August 2018 (BANCO protocol) and October 2019 (BANCO2 protocol). Recruitment is still in progress, and no analyses of the data have begun.

\section{Participants}

\section{Patient and Public Involvement Statement}

The patients and the public were not involved in the design, conduct, reporting, or dissemination plans of our research.

\section{Sample Size Calculation}

Given the exploratory aspect of this study and given the lack of data in the literature, sample size can be determined based only on recruiting capacities. Moreover, the sample sizes in case-control studies on $\mathrm{GmD}$ are usually quite small. For example, a recent meta-analysis exploring the inhibitory control abilities of participants with $\mathrm{GmD}^{61}$ reported the results of studies assessing only 11 participants in one study and more than 30 participants in another (mean $=21$ participants with $\mathrm{GmD}$ per study). Thus, this study is in the upper part of the range regarding the number of participants usually assessed.

\section{Description of the Population}

The participants included both patients with BAs and HCs. Patients were recruited from the Addictology Department of the University Hospital of Nantes. The patient groups will include 120 participants seeking treatment for a BA; more explicitly, GbD $(n=30), \operatorname{GmD}(n=30)$, SA $(n=30)$ and FA $(n=30)$. Each group is matched on sex, age, and level of education with a group of $30 \mathrm{HCs}$. The $120 \mathrm{HCs}$ are being recruited through media announcements (newspapers and radio), the Internet (link on the research team's website, institutional websites, professional networking), and the registry of volunteers for research that was constituted by the research team.

\section{Eligibility Criteria}

For all participants, the inclusion criteria are (i) being affiliated with the French healthcare system, (ii) being fluent in French (writing and reading), (iii) having appropriate 
levels of vision and hearing (with or without correction), and (iv) willing to accept the application of non-invasive electrodes. The non-inclusion criteria are (i) being under 15 years (for the FA, SA and GmD groups) and 18 for the GbD group as it is not legal to gamble before 18 years of age; (ii) presenting with current and non-stabilized cardiac, psychiatric, endocrine disorders or a lifetime psychotic disorder; (iii) presenting with a history of neurological disorders; (iv) receiving psychotropic treatment that had not been stabilized for at least two weeks; (v) presenting with colour blindness; (vi) underwent therapy focused on cognitive remediation; (vii) being under guardianship; (viii) presenting with a cognitive disorder that impacts daily functioning and could impact completion of the cognitive tasks described below; (ix) having participated in a clinical trial on a drug during the past month; (x) being pregnant; (xi) having electrical implants; (xii) having worked or studied in the field of psychology; and (xiii) having consumed psychoactive substances during the past 12 hours. To be included in one of the four patient groups, participants had to meet the diagnostic criteria of one of the BAs under study and to be at the beginning of their treatment (within six months after the first appointment with the clinician). Regarding the FA group, eating disorders are accepted as current psychiatric comorbid disorders because they are a core feature of FA. The restrictive type of anorexia nervosa is not allowed because the concept of FA is not particularly valid in this disorder. ${ }^{4}$ Table 1 presents measures used for the diagnosis of the BAs (patient groups).

\section{Procedure}

The first visit includes the collection of sociodemographic and clinical characteristics. The second visit includes the neurocognitive assessment. HCs complete both the clinical and neurocognitive assessments during the same visit (see Table 2 for a schedule). For patients, sociodemographic and clinical data are retrieved from the EVALADD cohort (NCT01248767).

The criteria for discontinuing or modifying the assessment (clinical or neuropsychological) is the withdrawal of consent, which leads to the cessation of the assessment, or the interruption of the assessment because of the health state of the participant (dizziness, anxiety, excessive fatigue, etc.), which could be followed by resumption of the assessment.

\section{Clinical Assessment}

The first visit included a standardized assessment of psychopathological characteristics, personality profile, and addiction-related characteristics (only for the patients) through self-reported questionnaires and clinical interviews. Table 3 presents the content of the clinical assessment. Moreover, the experimenters also collect data regarding the following:

- sociodemographic characteristics (sex, age, education level, professional status);

- current treatments; and

- history of addiction (age of onset, duration, and several characteristics) - only for the patients.

\section{Neurocognitive Assessment}

All participants (patients and HCs) performed the same assessment of neurocognitive functioning, including several cognitive tasks assessing a wide range of neurocognitive processes.

For several tasks, we use neutral, positive, negative, and addiction-related pictures (visual probe detection task, go-nogo task, stop-signal task, and cue-reactivity task) or words (Stroop task) (see Supporting Files S1 (Additional Tables 1 and 2)) for the image and word selection procedure). The use of emotional and addiction-related stimuli allows us to differentiate a bias towards addiction-related stimuli or to general emotional stimuli. ${ }^{164}$ Regarding the tasks using addiction-related pictures, we take into account the patient's preference using a personalized research perspective. Each addiction has a list of several modalities of pictures (see details in Table 4), and the participant has to choose two modalities (except for those with FA, who choose only one modality) that reflect his/her preferences.

Several cognitive tasks (visual probe detection task, go-nogo task, stop-signal task, Stroop task, delay discounting task, Iowa gambling task, and cue-reactivity task) are computerized (see Supporting File S2 for details of the software and apparatus used).

\section{Cognitive Tasks}

All the cognitive tasks used in the BANCO and BANCO2 studies are briefly described in this section, and more details are provided in Supporting File S3 (Additional Figure 1). The tasks are presented here in 
Table I Measures Used for the Diagnosis of BA

\begin{tabular}{|c|c|c|c|}
\hline Pathology & Diagnosis Criteria & Measures & Threshold \\
\hline $\begin{array}{l}\text { Gambling Disorder } \\
(G b D)\end{array}$ & $\begin{array}{l}\text { Gambling disorder section of the } \\
\text { DSM-5 }\end{array}$ & $\begin{array}{c}\text { NODS }^{82} \text { (fair internal reliability }{ }^{83} \text { ) adapted to the DSM-5 } \\
\text { criteria }\end{array}$ & Score $\geq 4$ \\
\hline $\begin{array}{l}\text { Sexual Addiction } \\
\text { (SA) }\end{array}$ & $\begin{array}{l}\text { Diagnostic criteria proposed by } \\
\text { Carnes, Hopkins, and Green }(2014)^{84}\end{array}$ & $\begin{array}{l}\text { In the absence of a validated diagnostic interview, the } \\
\text { structure of the NODS is used, after adoption of Carnes' } \\
\text { diagnosis criteria }\end{array}$ & Score $\geq 3$ \\
\hline $\begin{array}{l}\text { Gaming Disorder } \\
(\mathrm{GmD})\end{array}$ & $\begin{array}{l}\text { Internet gaming disorder section of } \\
\text { the DSM-5 and gaming disorder } \\
\text { section of the ICD-II }\end{array}$ & $\begin{array}{l}\text { In the absence of a validated diagnostic interview, the } \\
\text { structure of the NODS is used, after adaptation to the DSM- } 5 \\
\text { criteria for internet gaming disorder. } \\
\text { Moreover, the experimenter systematically questions patients } \\
\text { to ensure that they meet the definition of gaming disorder, as } \\
\text { proposed in the ICD-I I }\end{array}$ & Score $\geq 5$ \\
\hline $\begin{array}{l}\text { Food Addiction } \\
\text { (FA) }\end{array}$ & $\begin{array}{l}\text { Substances dependence criteria of the } \\
\text { DSM-5 }\end{array}$ & YFAS 2.0 (French validation, good internal consistency ${ }^{85}$ ) & $\begin{array}{l}\text { Score } \geq 2 \\
\text { AND significant } \\
\text { distress }\end{array}$ \\
\hline
\end{tabular}

Abbreviations: DSM: Diagnostic and Statistical Manual of Mental Disorders; NODS: National Opinion Research Center DSM Screen for Gambling Problems; ICD: International Classification of Disease; YFAS: Yale Food Addiction Scale

Table 2 Schedule of Enrolment and Assessments Following SPIRIT Guidelines ${ }^{86,87}$

\begin{tabular}{|c|c|c|c|}
\hline & \multicolumn{3}{|c|}{ Study Period } \\
\hline & \multicolumn{2}{|c|}{ Patient Groups } & \multirow{2}{*}{$\frac{\text { Control Group }}{\text { Enrolment and Assessment }}$} \\
\hline & Enrolment & Assessment & \\
\hline TIMEPOINT & $-t_{1} *$ & $\mathrm{t}_{0}$ ** & $\mathrm{t}_{0} * *$ \\
\hline ENROLMENT: & & & \\
\hline Eligibility screen & $\mathrm{X}$ & & $x$ \\
\hline Informed consent & $x$ & & $x$ \\
\hline ASSESSMENTS: & & & \\
\hline Clinical Assessment & $x$ & & $x$ \\
\hline Neurocognitive assessment & & $x$ & $\mathrm{X}$ \\
\hline
\end{tabular}

Notes: *Less than six month before t0; **Time zero, the day of the neurocognitive assessment, $\mathrm{X}$ : indicates the timepoint of each step of the study.

their order of presentation to the participants. For all of the tasks (except the cue-reactivity task), we include a concurrent assessment of metacognitive abilities (ie, the ability to appraise, monitor, and control our thoughts). ${ }^{12,113}$ Indeed, we ask the participant to selfrate his/her capacity to correctly perform a specific task before and after completing each task, which provides concurrent access to both appraisal and monitoring assessments. This form of metacognition assessment does not increase cognitive load because monitoring is not carried out during the task. ${ }^{114}$ Moreover, to capture this measure, we use a modified version of the Positive/ Negative Behavioral Addiction Metacognition Scale (PBAMS/NBAMS), ${ }^{115}$ which is a self-report questionnaire that assesses participants' general knowledge of their metacognitive capacities.

$d^{2}$

The first cognitive task is the $\mathrm{d}^{2}$ task, which is a standardized and normalized test assessing sustained attention. The participant is instructed to find a target (a "d" with two points) among distractors ("p" or a "d" with 1 or more than 2 points). ${ }^{116}$ 
Table 3 Measures Used for the Clinical Assessment

\begin{tabular}{|c|c|c|}
\hline & Measures Used & $\begin{array}{l}\text { Clinical Data } \\
\text { Obtained }\end{array}$ \\
\hline \multirow[t]{5}{*}{ Psychopathological characteristics } & $\begin{array}{l}\text { HAD (Hospital Anxiety and Depression Scale) }{ }^{88} \text { (self-reported } \\
\text { questionnaire, good reliability and discriminant validity) }\end{array}$ & $\begin{array}{l}\text { Presence and severity of } \\
\text { depression and anxiety } \\
\text { symptoms }\end{array}$ \\
\hline & $\begin{array}{l}\text { MINI (Mini International Neuropsychiatric Interview, good } \\
\text { sensitivity and specificity) }\end{array}$ & $\begin{array}{l}\text { Screening of psychiatric } \\
\text { and addictive disorders }\end{array}$ \\
\hline & $\begin{array}{l}\text { MIDI (Minnesota Impulsive Disorder Interview, good discriminant } \\
\text { validity) }{ }^{9 !}\end{array}$ & $\begin{array}{l}\text { Screening of comorbid } \\
\text { BAs }\end{array}$ \\
\hline & $\begin{array}{l}\text { WURCS-C (Wender Utah Rating Scale-short version) }{ }^{92} \text { (self- } \\
\text { reported questionnaire, adequate internal consistency) }\end{array}$ & $\begin{array}{l}\text { Retrospective screening } \\
\text { of ADHD during } \\
\text { childhood }\end{array}$ \\
\hline & $\begin{array}{l}\text { ASRS (Adult ADHD Self-Report Scale Symptom Checklist) } \\
\text { (self-reported questionnaire with a good sensitivity in a substance } \\
\text { use disorder population) }\end{array}$ & $\begin{array}{l}\text { Presence of ADHD } \\
\text { symptoms in adulthood }\end{array}$ \\
\hline \multirow{4}{*}{$\begin{array}{l}\text { Addiction-related characteristics (only for } \\
\text { participants for who the associated section of the } \\
\text { MIDI is positive) }\end{array}$} & $\begin{array}{l}\text { CPGI (Canadian Problem Gambling Index) }{ }^{96} \text { (self-reported } \\
\text { questionnaire with adequate reliability) }\end{array}$ & $\begin{array}{l}\text { Severity of gambling } \\
\text { disorder }\end{array}$ \\
\hline & $\begin{array}{l}\text { PIUQ-JV (Problematic Internet Use Questionnaire), }{ }^{97} \text { adapted for } \\
\text { videogames (self-reported questionnaire with adequate } \\
\text { psychometric proprieties calculated across nine European } \\
\text { countries) }{ }^{98}\end{array}$ & $\begin{array}{l}\text { Severity of excessive use } \\
\text { of videogames }\end{array}$ \\
\hline & $\begin{array}{l}\text { SAST-R (Sexual Addiction Screening Test-Revised) } \\
\text { reported questionnaire with an excellent internal consistency) } \\
\text { reo }\end{array}$ & $\begin{array}{l}\text { Severity of sexual } \\
\text { addiction }\end{array}$ \\
\hline & $\begin{array}{l}\text { EDI-2 (Eating Disorders Inventory-2) }{ }^{101} \text { (self-reported } \\
\text { questionnaire with acceptable internal consistency in a binge } \\
\text { eating disorder population) }{ }^{102}\end{array}$ & $\begin{array}{l}\text { Severity of eating } \\
\text { disorders on multiple } \\
\text { aspects }\end{array}$ \\
\hline \multirow[t]{4}{*}{ Personality } & $\begin{array}{l}\text { UPPS-P (Impulsive Behavior Scale) }{ }^{103} \text { (self-reported questionnaire } \\
\text { with a good internal reliability) }\end{array}$ & Impulsivity profile \\
\hline & $\begin{array}{l}\text { RSES (Rosenberg Self-Esteem Scale) }{ }^{105} \text { (self-reported } \\
\text { questionnaire with acceptable validity and fidelity) }\end{array}$ & level of self-esteem \\
\hline & $\begin{array}{l}\text { TCl-I } 25 \text { (Temperament and Character Inventory) }{ }^{107} \text { (self- } \\
\text { reported questionnaire with a good internal consistency) }{ }^{108}\end{array}$ & $\begin{array}{l}\text { Temperament and } \\
\text { character profile }\end{array}$ \\
\hline & $\begin{array}{l}\text { TAS-20 (Toronto Alexithymia Scale) }{ }^{109} \text { (self-reported } \\
\text { questionnaire) }\end{array}$ & Alexithymia profile \\
\hline
\end{tabular}

Table 4 Modalities Proposed for Addiction-Related Pictures

\begin{tabular}{|l|l|}
\hline Addiction & Proposed Modalities for Addiction-Related Pictures \\
\hline GbD & Poker, casino, lotteries, sports betting, horse betting \\
GmD & MMORPG (massively-multiplayer online role-playing game), FPS (first person shooter), MOBA (multiplayer online battle area), and \\
& $\begin{array}{l}\text { Sandbox and RTS (real-time strategy) together } \\
\text { SA }\end{array}$ \\
FA & Swoman alone, women, a man alone, men, man and woman together \\
\hline
\end{tabular}

Abbreviations: $\mathrm{GbD}$, gambling disorder; GmD, gaming disorder; SA, sexual addiction; FA, food addiction. 
Difference scores permit an evaluation of visual sustained attention capacities independent of processing speed abilities.

\section{Stroop Task}

This modified version of the Stroop task is used to assess cognitive inhibitory control related to addiction, as done in several studies. ${ }^{66,117-119}$ As in the original task, the first three parts include (i) the denomination of colours, (ii) the reading of words designating colours, and (iii) the designation of the colour of the ink in which words are written. ${ }^{120,121}$ In the added emotional part of this modified version, the participant has to designate the colour of the ink in which negative, positive, neutral, and addiction-related words are written. This emotional part assesses the automatic treatment of emotional words and the presence of an interference bias towards words related to addiction. ${ }^{166,167}$

\section{Cue Reactivity}

Cue reactivity (ie, arousal and valence processing of stimuli) is measured by both subjective and objective measures. ${ }^{122}$ All pictures (neutral, positive, negative, and addiction-related) used for the other tasks (visual dot-probe, stop-signal, and go-nogo tasks) are presented one by one in the cue-reactivity task (which is the first computerized task that includes pictures). The participants simply look at the pictures, while several physiological indices are recorded to assess the objective emotional activation produced by pictures. The physiological indices are the inter-beat interval, skin conductance responses, and electromyography (EMG) of the corrugator supercilium and the zygomaticus major. Inter-beat interval and skin conductance measures provide information about the autonomic nervous system responses to stimuli and about whether the patients respond to addiction-related pictures differently than emotional or neutral pictures and control participants. The two EMG electrodes permit us to distinguish a negative from a positive facial reaction. ${ }^{165}$ Afterward, participants subjectively rated the emotional valence and arousal of each picture, as well as the level of connection with the object of addiction (sex, gambling, food, or videogame). Each subjective assessment is performed on a scale ranging from 1 to 5 . In addition to providing a subjective and objective rating of our material, this task allows us to ensure that the pictures are perceived as anticipated.

\section{Visual Probe Detection Task (VDP)}

This task explores selective attention. A pair of pictures (one is neutral, and the other one is the cue of interest, which could be neutral, positive, negative, or addiction- related) is presented on the screen to the left and right of a fixation cross. ${ }^{123}$ The pictures are then replaced by a target that appears either to the right or the left of the fixation cross, and the participant has to detect the target as quickly as possible. Compared to the $\mathrm{d}^{2}$ task, the visual probe detection task allows the identification of bias of engagement (congruent condition, with the target appearing at the same position as the cue of interest) and disengagement (incongruent condition, with the target appearing at the opposite position of the cue of interest) of attention towards emotional and addiction-related stimuli.

\section{lowa Gambling Task (IGT)}

This task is used to evaluate decision making under uncertain conditions and was initially developed to assess patients with ventromedial prefrontal cortex lesions. ${ }^{44,124}$ This task is a computerized ecological task, and level of performance has been associated with the reward system and inhibitory control abilities. ${ }^{125,126}$ The participants are instructed to choose between 4 possible decks of cards (A, $\mathrm{B}, \mathrm{C}$, and D). ${ }^{127,128}$ Each decision triggers a monetary gain but sometimes also a penalty that leads to a net loss. The level of gain and penalties vary between decks, which results in two advantageous decks and two disadvantageous decks. Behavioral and physiological responses associated with decisions are measured.

\section{Verbal Fluency Tasks}

This task assesses spontaneous flexibility, ie, the flow of available ideas and the ability to generate many answers to one question by switching from category to category. The participants provide as many words beginning with the letter $\mathrm{P}$ as possible in two minutes (phonological modality) without saying the same word twice, without saying two words from the same family, and without saying a proper noun. ${ }^{129}$ The participants do this task a second time, but they have to provide as many words as possible that belong to a particular category (here, animals; lexical modality).

\section{Trail Making Test (TMT)}

This task $^{130}$ evaluates reactive flexibility, which is the ability to switch from one set of operating rules to others and to adapt ways of thinking and acting depending on the context. ${ }^{131}$ This task is a paper-and-pencil task in which participants must link encircled numbers (from 1 to 25 ) in increasing order (TMT-A). In the second part (TMT-B), the participants need to switch between two operating 
rules by alternately connecting numbers from 1 to 13 and letters from A to L. In the two parts, the participants must not lift their pen from the paper and must complete the task as fast as possible. ${ }^{132}$

\section{Modified Wisconsin Card Sorting Test (M-WCST)}

This $\operatorname{task}^{133}$ also assesses reactive flexiblity and rule deduction. The participants are given a deck of 48 cards that they have to match with 4 stimulus cards placed in front of them on the table No information is given to the participant about how to match the cards, but the experimenter gives feedback on whether the match is right or wrong so that the participant can deduce the correct rule. Rules change during the task, and the experimenter informs the participant when this occurs so that the participant has to switch the type of matching to find the new rule.

\section{French Version of the National Adult Reading Test (fNART)}

The fNART measures premorbid intellectual efficiency. ${ }^{134}$ It comprises a list of complicated words that do not follow usual pronunciation rules, and the participants have to read the list aloud. A good correlation between the English version of the NART and Wechsler Adult Intelligence Scale (WAIS-IV) performances, specifically the general ability index and the verbal comprehension index, has been shown in the healthy population. ${ }^{135}$ This measure permits us to control for the premorbid intelligence level of all participants and to take this variable into account as a confounding factor.

\section{Complex Rey-Osterrieth Figure}

This paper-and-pencil task involves a rectangle that surrounds and is surrounded by geometrical forms. ${ }^{136}$ The patients are instructed to copy it, which permits us to observe visuoconstruction abilities. Moreover, the way the participant builds his drawing (begins with the central rectangle, draws it element by element or even stroke by stroke) is an indicator of organizational strategies ${ }^{137,138}$ and thus planning abilities. The experimenter records the order in which participants draw the elements, the score of the copy and time taken to realize the drawing. The technique of switching colours of the pens every 30 seconds is not used, as this technique stops participants during their drawing and distracts them; therefore, a precise measure of time taken to draw is obtained. ${ }^{137}$

\section{Hanoï Tower}

Regarding cognitive planning abilities, ie, the capacity to anticipate and think ahead about the best way to properly perform a task, the Hanoï test is used to assess nonverbal planning abilities handled by the frontal lobe ${ }^{139}$ by means of a board with three tubes and five discs of different sizes. The participants have to put their board into the same arrangement as shown in the model (final position disposition). They must use the minimum number of moves possible, cannot move two discs at the same time, and cannot put a larger disc on a smaller one.

\section{Squares (Subtest of the WAIS-IV Scale)}

This task assesses visuospatial processing. ${ }^{140}$ In this task, the participant is given 4 to 9 identical cubes (each of them with two white sides, two red sides, and two bicolour sides). Then, the experimenter shows the participant several paper sheets (up to 14), each with the model to be reproduced by the participant, including a specific pattern on the top of the cubes. The experimenter records scores with and without time bonuses to observe the impact of speed processing on participant performance.

\section{Go-Nogo Task}

This task permits the assessment of the ability to stop an automatic response induced by stimuli (motor inhibition). ${ }^{141}$ The participants are asked to press a button as fast as possible when the go signal is presented and to not press the button when the nogo signal appears. The go signals are much more numerous than nogo signals to maintain the urge to respond. We use an emotional version of the task, ${ }^{142,143,168}$ in which go and nogo signals include a background with neutral, positive, negative, or addiction-related pictures.

\section{Single Key Impulsivity Paradigm (SKIP)}

This task assesses the tolerance for delayed rewards. The SKIP task is a "free operant procedure", ${ }^{144}$ which means that the procedure does not include multiple trials with discrete possible answers. Over the 10 minutes, the participants can press a button whenever they want to obtain points, which are given in proportion to the delay between consecutive responses (the longer the delay is, the greater the number of points). 
Mini Social and Cognition and Emotional Assessment (Mini-SEA)

The mini-SEA ${ }^{145}$ includes two subtests: the "faux pas" task and an emotion recognition task.

\section{"Faux Pas" Task}

The participants read 10 stories in which they have to detect if one of the characters made a social mistake by accident. Five of the 10 stories are distractors, meaning that there is no social mistake in it. For each story, the experimenter asks control questions to ensure that the participant has well understood the situation and other questions to assess the detection of the mistake.

\section{Emotion Recognition}

This task consists of the presentation of 35 pictures of faces in black and white on a paper sheet. The participants have to choose which emotions are displayed by the faces from among seven possible answers (surprise, happiness, fear, angriness, sadness, neutral, disgust). Reaction times are not collected, but the participants are instructed to spontaneously answer with a 12 -second maximum.

\section{Stop-Signal Task (SST)}

This task assesses the ability to interrupt an already initiated motor response in a context where automatic inhibition is unlikely to occur. The participants are asked to categorize a target (arrow directed to the left or the right), but in a quarter of the trials, an audio stop signal occurs with a variable delay, and the participant has to refrain from responding. We use an emotional version ${ }^{146}$ in which the target includes a background with neutral, positive, negative, or addiction-related pictures.

\section{Data Management}

All included participants are given an identification number, depending on the group of inclusion. The link between numbers and the identity of the patients is accessible only to authorized members and is kept separate from the research data. This data will be available only to units involved in this project (Addictology Department of the CHU of Nantes and the biometry platform from the University Hospital of Nantes). The data from the computerized tasks are processed with Excel and R programs. The data from neuropsychological tasks that are not computerized are collected on the case report form. All collected data are then entered and coded with EpiData software (EpiData Association, http://www.epidata.dk). This software is hosted on a hospital server and is therefore accessible only to authorized members.

\section{Statistical Analysis}

To compare the global level of cognitive functioning of that patients with that of the HCs, a composite score will be created based on all the cognitive measures. It will be computed based on a principal component analysis performed on all the cognitive measures by retaining only the principal dimension as a latent variable. For each group of patients, linear models will be used to compare the composite scores of individuals with BAs to their matched HCs, including a random effect on matched patient/HC pairs. Moreover, to identify which specific cognitive functions are altered in individuals with BAs, each cognitive measure will be independently compared between the patients and their matched HCs. Logistic models (for qualitative outcomes) and/or linear models (for quantitative outcomes), including a random effect on matched patient/HC pairs, will be performed.

To identify specific alterations linked to each BA and to explore common deficits across different BAs, the composite scores and each cognitive measure will be compared between each pair of patient groups. Linear models explaining the composite score and the neurocognitive scores by the BA group will be performed.

Finally, a multidimensional descriptive analysis (principal component analysis) will be performed to investigate the links between clinical data and cognitive test performance.

All the analyses will control for possible confounding factors that may affect performance in the different cognitive tasks (for example, the premorbid intelligence level, the history of attention-deficit/hyperactivity disorder or past substance -use disorders). In the case of a significant difference between the two groups, confounding factors will be entered as covariates in the statistical analyses.

In the case of premature cessation of the assessment or missing data, the missing data will be imputed with a "worst case" scenario (ie, by replacing the missing data with the worst value obtained in that participant's group). For variables in which 10 to $20 \%$ of data are missing, a sensitivity analysis will be performed by testing other scenarios (imputation by the mean, multiple imputation, 
etc.). If more than $20 \%$ of the data are missing, the data will not be imputed.

\section{Monitoring}

No data monitoring committee is needed because this research involves only benign risks for the participants. No unintended effects of the trial are expected.

\section{Discussion}

\section{Expected Results and Clinical Implications}

This study has several perspectives, both from scientific and clinical points of view.

From a scientific point of view, the results may provide new knowledge regarding the cognitive functioning of patients with BAs and open several areas of research. First, the results will provide new information regarding common patterns between different BAs and will contribute to the debate regarding the inclusion of BAs in the addictive spectrum. More specifically, this research programme will contribute to extending the literature regarding underexplored BAs, such as SA and FA. Indeed, in 2013, GmD was considered in need of further research before inclusion in the "Substances-related and addictive disorders" in the DSM-5 and recognition as a BA in the ICD-11, while GbD was recognized in 2013 in the DSM-5 and in 2018 in the ICD-11. This gradual inclusion in international classification systems shows that BAs are becoming increasingly recognized. FA and SA need further research to improve their assessment and clarify their characteristics ${ }^{2,147}$ before considering their possible inclusion as addictive disorders in these international classification systems. Second, the exploration of BAs represents an interesting model for increasing knowledge on the cognitive alterations involved in addictive disorders in general. Indeed, as BAs do not involve the consumption of psychoactive substances, this research programme will also provide a better understanding of the cognitive processes that underlie substance-related addictive disorders. ${ }^{148}$ This is because the ingestion of psychoactive substances alters neurocognitive functioning and may influence the evaluation of cognitive mechanisms underlying addiction in those with substance use disorders. ${ }^{149}$ Finally, this study explores cognitive functions that are still underexplored, such as social cognition and metacognition $^{58,59}$ and will provide new results examining functions that have produced mixed results, such as flexibility or decision making. ${ }^{53}$ This will permit a better understanding of common and specific neurocognitive patterns in several
BAs and improve the understanding of the factors that trigger and maintain BAs and addictions in general.

From a clinical perspective, several applications may be considered. First, the inclusion of these BAs in the addictive spectrum would permit the development of pan-addiction treatments for both substance-related and other addictive disorders. Knowledge about the clinical management of substance use disorders could benefit patients presenting with BAs. ${ }^{150-152}$ For example, molecules already tested for substance use disorders may also be used for BAs. This is the case for opioid antagonists such as naltrexone, which was tested in patients with compulsive sexual behavior ${ }^{22}$ or $\mathrm{GbD},{ }^{153,154}$ or nalmefene, which was tested in patients with GbD. ${ }^{155}$ Moreover, a transversal approach would permit clinicians to not surcharge for multiple therapies and improve the impact of therapies because of co-occurrences. ${ }^{41}$ Indeed, when comparing patients with both an alcohol use disorder and a BA to patients with only an alcohol use disorder, it seems that the presence of the BA is linked with increased craving and impulsivity. ${ }^{150}$ Co-occurrences of substance use disorder and BAs thus seem to impact treatment. Treating both addictions as a unique entity would permit us to focus therapy on common underlying processes using, for example, motivational interviewing or cognitive therapy, rather than trying to treat two distinct mental disorders. Second, increasing knowledge about specific cognitive alterations could permit the development of new therapies focused on such deficits. In fact, in the field of addiction, cognitive remediation therapy has mainly been developed for substance use disorder, in which it showed the reversibility of cognitive alterations linked to the ingestion of psychoactive substances through top-down ${ }^{156,157}$ and bottom-up ${ }^{158}$ therapies. Nevertheless, the impact of these therapies on addictive behaviors requires further research. ${ }^{159}$ Regarding BAs, there are ongoing cognitive remediation programmes for individuals with GbD, even if no formal efficacy has been demonstrated. ${ }^{59,160}$ Moreover, a programme of cognitive bias modification showed preliminary positive findings regarding the diminution of urges and cue reactivity for those with GmD. ${ }^{161}$ However, despite growing evidence regarding the importance of cognitive functioning in BAs, further research is needed to better characterize the cognitive profiles to build specific cognitive remediation programmes. Finally, it has been shown that cognitive functioning, and more specifically impulsive decision making, impacts the efficacy of treatment in individuals with substance use disorders. ${ }^{159,162}$ Moreover, research has shown in a group of $\mathrm{GmD}$ patients that the amelioration of clinical symptoms 
seems to be accompanied by improvements in neurocognitive functioning after six months of outpatient treatment. ${ }^{163}$ Thus, these studies show the importance of taking cognitive functioning into account when trying to understand and treat addictive mechanisms. ${ }^{45}$

\section{Limits}

There are several eligibility criteria that do not permit the inclusion of all patients in our service. Therefore, this study will last at least two years, but it will permit us to reduce bias linked to confounding factors such as psychiatric comorbidities and to observe the neuropsychological profile linked to a particular BA. Moreover, this study is exploratory and will need to be replicated by others to confirm the results. Finally, this study adopts a cross-sectional design, while a longitudinal design would have provided more information. Indeed, this latter type of study would have permitted an assessment of changes in assess cognitive functioning in connection with relapses or abstinence or the impact of the level of cognitive functioning on treatment. Nevertheless, characterizing the cognitive profile at the beginning of treatment may permit the assessment of outstanding features specific to BAs that can be assessed longitudinally in subsequent studies to assess the links between cognition and BAs throughout treatment, relapse or abstinence.

\section{Dissemination Policy}

The results of this study will be communicated to participants (collective results) and to the scientific community by means of oral communications, scientific articles, and a Ph.D. thesis. All research employees involved in the study may communicate about this research. Scientific articles may be edited by professionals for issues related to the English language.

\section{Data Sharing Statement}

The datasets generated and/or analysed during the current study will not be publicly available due the presence of private and medical data but will be available from the corresponding author on reasonable request.

\section{Ethics Approval and Consent to Participate}

This research programme is conducted following Good Clinical Practice Guidelines and the Declaration of Helsinki, with approval from the French national ethics committee (Comité de Protection des Personnes; CPP OUEST III for BANCO and SUD-EST VI for BANCO2).
All participants provided written informed consent collected by investigators. An amount of $€ 75$ is given to compensate for the travel costs incurred for the research visit.

\section{Acknowledgments}

The authors thank Pr. Marcantonio Spada for his authorization to adapt (for BAs) and translate (in French) the Positive/Negative Behavioral Addiction Metacognition Scale (PBAMS/NBAMS).

\section{Author Contributions}

All authors made substantial contributions to conception and design, acquisition of data, or analysis and interpretation of data; took part in drafting the article or revising it critically for important intellectual content; agreed to submit to the current journal; gave final approval of the version to be published; and agree to be accountable for all aspects of the work.

\section{Funding}

This work was supported through the First Scientific Prize from the MILDECA (Mission Interministérielle de Lutte contre les Drogues Et les Conduites Addictives), obtained by Pr Marie Grall-Bronnec and her team in 2016 for the operating costs of the BANCO study. The operating costs of the BANCO2 study are self-funded by the Nantes University Hospital. The costs associated with the neuropsychological assessments are covered by a doctoral allowance from the University of Nantes in the framework of the Ph.D. scholarship of EH. Award/grant numbers are not applicable. The funders had no role in the study design, data collection and analysis, decision to publish, or preparation of the manuscript. The CHU of Nantes is the sponsor of the study (Direction des Affaires Médicales et de la Recherche, 5, allée de l'île Gloriette, 44093 Nantes cedex 01 (FRANCE), +33 02534828 35).

\section{Disclosure}

MBG, ET, AS and GCB declare that the endowment funds of the Nantes University Hospital have received funding from the gambling industry (FDJ and PMU) in the form of a philanthropic sponsorship (donations that do not assign purpose of use). Scientific independence with respect to these gambling industries is guaranteed, and they neither take part in the study design nor exert any editorial influence over this article. EH reports grants from University of Nantes, during the conduct of the study ( $\mathrm{PhD}$ funding). Jean-Benoit 
Hardouin has nothing to disclose. The authors report no other potential conflicts of interest for this work.

\section{References}

1. Goodman A. Addiction: definition and implications. Addiction. 1990;85(11):1403-1408. doi:10.1111/j.1360-0443.1990.tb01620.x

2. American Psychiatry Association. DSM-5: Diagnostic and Statistical Manual of Mental Disorders. Washington, DC: American Psychiatric Publishing; 2013.

3. Goodman A. What's in a name? Terminology for designating a syndrome of driven sexual behavior. Sex Addict Compulsivity. 2001;8:191-213. doi:10.1080/107201601753459919

4. Hebebrand J, Albayrak Ö, Adan R, et al. "Eating addiction", rather than "food addiction", better captures addictive-like eating behavior. Neurosci Biobehav Rev. 2014;47:295-306. doi:10.1016/ j.neubiorev.2014.08.016

5. Meule A. Back by popular demand: a Narrative review on the history of food addiction research. Yale $J$ Biol Med. 2015;88:295-302.

6. Chen W-J. Frequent exercise: a healthy habit or a behavioral addiction? Chronic Dis Transl Med. 2016;2:235-240. doi:10.1016/j.cdtm.2016.11.014

7. Cuzen NL, Stein DJ. Chapter 2 - Behavioral addiction: the Nexus of impulsivity and compulsivity. In: Rosenberg KP, Feder LC, editors. Behavioral Addictions. San Diego: Academic Press; 2014:19-34. doi:10.1016/B978-0-12-407724-9.00002-1

8. Hussain N, Guanci N, Raza M, Ostrovsky D. Shopping addiction. If the shoes fits, buy it in every color! In: Ascher M, Levounis P, editors. The Behavioral Addictions. American Psychiatric Pub; 2015.

9. Griffiths MD. Compulsive sexual behaviour as a behavioural addiction: the impact of the internet and other issues. Addiction. 2016;111(12):2107-2108. doi:10.1111/add.13315

10. Kraus SW, Voon V, Potenza MN. Should compulsive sexual behavior be considered an addiction? Addiction. 2016;111 (12):2097-2106. doi:10.1111/add.13297

11. Schulte EM, Potenza MN, Gearhardt AN. A commentary on the "eating addiction" versus "food addiction" perspectives on addictive-like food consumption. Appetite. 2017;115:9-15. doi:10.1016/j.appet.2016.10.033

12. Chamberlain SR, Grant JE. Behavioral Addictions. 1st ed. In: Fontenelle LF, Yücel M, editors. A Transdiagnostic Approach to Obsessions, Compulsions and Related Phenomena. 1st Ed. Cambridge University Press; 2019:401-412. doi:10.1017/ 9781108164313.032

13. Kraus SW, Krueger RB, Briken P, et al. Compulsive sexual behaviour disorder in the ICD-11. World Psychiatry. 2018;17 (1):109-110. doi:10.1002/wps.20499

14. World Health Organization. International Classification of Diseases (11th Revision); 2018.

15. Goodman A. Neurobiology of addiction. An integrative review. Biochem Pharmacol. 2008;75:266-322.

16. Kühn S, Gallinat J. Chapter Three - Neurobiological basis of hypersexuality. In: Zahr NM, Peterson ET, editors. International Review of Neurobiology. Academic Press; 2016:67-83. doi:10.1016/bs.irn.2016.04.002

17. Garcia FD, Thibaut F. Sexual addictions. Am J Drug Alcohol Abuse. 2010;36(5):254-260. doi:10.3109/00952990.2010.503823

18. Antons S, Mueller SM, Wegmann E, Trotzke P, Schulte MM, Brand M. Facets of impulsivity and related aspects differentiate among recreational and unregulated use of Internet pornography. J Behav Addict. 2019;8:223-233. doi:10.1556/2006.8.2019.22
19. Gola M, Wordecha M, Sescousse G, et al. Can pornography be addictive? An fMRI Study of men seeking treatment for problematic pornography use. Neuropsychopharmacol. 2017;42:2021-2031. doi:10.1038/npp.2017.78

20. Voon V, Mole TB, Banca P, et al. Neural correlates of sexual cue reactivity in individuals with and without compulsive sexual behaviours. PLoS One. 2014;9(7):e102419. doi:10.1371/journal. pone.0102419

21. Kowalewska E, Grubbs JB, Potenza MN, Gola M, Draps M, Kraus SW. Neurocognitive mechanisms in compulsive sexual behavior disorder. Curr Sex Health Rep. 2018;10:255-264. doi:10.1007/s11930-018-0176-z

22. Leppink EW, Grant JE. Behavioral and pharmacological treatment of compulsive sexual behavior/problematic hypersexuality. Curr Addict Rep. 2016;3(4):406-413. doi:10.1007/s40429-0160122-y

23. Raymond NC, Grant JE, Coleman E. Augmentation with naltrexone to treat compulsive sexual behavior: a case series. Ann Clin Psychiatry. 2010;22:56-62.

24. Verholleman A, Victorri-Vigneau C, Laforgue E, Derkinderen P, Verstuyft C, Grall-Bronnec M. Naltrexone use in treating hypersexuality induced by dopamine replacement therapy: impact of OPRM1 A/G polymorphism on its effectiveness. Int $J$ Mol Sci. 2020;21:3002. doi:10.3390/ijms21083002

25. Potenza MN, Gola M, Voon V, Kor A, Kraus SW. Is excessive sexual behaviour an addictive disorder? Lancet Psychiatry. 2017;4(9):663-664. doi:10.1016/S2215-0366(17)30316-4

26. Imperatori $C$, Fabbricatore $M$, Vumbaca V, Innamorati $M$, Contardi A, Farina B. Food addiction: definition, measurement and prevalence in healthy subjects and in patients with eating disorders. Riv Psichiatr. 2016;51:60-65. doi:10.1708/2246.24196

27. Meule A, Gearhardt AN. Food addiction in the light of DSM-5. Nutrients. 2014;6(9):3653-3671. doi:10.3390/nu6093653

28. Corsica JA, Pelchat ML. Food addiction: true or false? Curr Opin Gastroenterol. 2010;26(2):165-169. doi:10.1097/MOG.0b013e $328336528 \mathrm{~d}$

29. Gearhardt AN, Corbin WR, Brownell KD. Preliminary validation of the Yale Food Addiction Scale. Appetite. 2009;52(2):430-436. doi:10.1016/j.appet.2008.12.003

30. de Vries S-K, Meule A. Food addiction and bulimia nervosa: new data based on the Yale Food Addiction Scale 2.0. Eur Eat Disord Rev. 2016;24(6):518-522. doi:10.1002/erv.2470

31. Granero R, Hilker I, Agüera Z, et al. Food addiction in a Spanish sample of eating disorders: DSM-5 diagnostic subtype differentiation and validation data. Eur Eat Disord Rev. 2014;22 (6):389-396. doi:10.1002/erv.2311

32. Leslie M, Lambert E, Treasure J. Towards a translational approach to food addiction: implications for bulimia nervosa. Curr Addict Rep. 2019;6(3):258-265. doi:10.1007/s40429-01900264-0

33. Hilker I, Sánchez I, Steward T, et al. Food addiction in bulimia nervosa: clinical correlates and association with response to a brief psychoeducational intervention. Eur Eat Disord Rev. 2016;24(6):482-488. doi:10.1002/erv.2473

34. Gearhardt AN, Yokum S, Orr PT, Stice E, Corbin WR, Brownell KD. Neural correlates of food addiction. Arch Gen Psychiatry. 2011;68:808-816. doi:10.1001/archgenpsychiatry.2011.32

35. Kalon E, Hong JY, Tobin C, Schulte T. Chapter Four - Psychological and neurobiological correlates of food addiction. In: Zahr NM, Peterson ET, editors. International Review of Neurobiology. Academic Press; 2016:85-110. doi:10.1016/bs.irn.2016.06.003

36. Wang GJ, Volkow ND, Logan J, et al. Brain dopamine and obesity. Lancet. 2001;357:354-357. doi:10.1016/s0140-6736(00) 03643-6 
37. Lindgren E, Gray K, Miller G, et al. Food addiction: a common neurobiological mechanism with drug abuse. Front Biosci (Landmark Ed). 2018;23:811-836. doi:10.2741/4618

38. Stoeckel LE, Weller RE, Cook EW, Twieg DB, Knowlton RC, Cox JE. Widespread reward-system activation in obese women in response to pictures of high-calorie foods. Neuroimage. 2008;41:636-647. doi:10.1016/j.neuroimage.2008.02.031

39. Meule A, Küppers C, Harms L, et al. Food cue-induced craving in individuals with bulimia nervosa and binge-eating disorder. PLoS One. 2018;13:e0204151. doi:10.1371/journal.pone.0204151

40. Gordon EL, Ariel-Donges AH, Bauman V, Merlo LJ. What is the evidence for "Food Addiction?" A systematic review. Nutrients. 2018;10(4):477. doi:10.3390/nu10040477

41. Kim HS, Hodgins DC. Component model of addiction treatment: a pragmatic transdiagnostic treatment model of behavioral and substance addictions. Front Psychiatry. 2018;9. doi:10.3389/ fpsyt.2018.00406

42. Brand M, Wegmann E, Stark R, et al. The Interaction of Person-Affect-Cognition-Execution (I-PACE) model for addictive behaviors: update, generalization to addictive behaviors beyond internet-use disorders, and specification of the process character of addictive behaviors. Neurosci Biobehav Rev. 2019;104:1-10. doi:10.1016/j.neubiorev.2019.06.032

43. Brand M, Young KS, Laier C, Wölfling K, Potenza MN. Integrating psychological and neurobiological considerations regarding the development and maintenance of specific Internet-use disorders: an Interaction of Person-Affect-CognitionExecution (I-PACE) model. Neurosci Biobehav Rev. 2016;71:252-266. doi:10.1016/j.neubiorev.2016.08.033

44. Bechara A. Decision making, impulse control and loss of willpower to resist drugs: a neurocognitive perspective. Nat Neurosci. 2005;8:1458-1463. doi:10.1038/nn1584

45. Noel X, Brevers D, Bechara A. A neurocognitive approach to understanding the neurobiology of addiction. Curr Opin Neurobiol. 2013;23(4):632-638. doi:10.1016/j.conb.2013.01.018

46. Wei L, Zhang S, Turel O, Bechara A, He Q. A tripartite neurocognitive model of internet gaming disorder. Front Psychiatry. 2017;8. doi:10.3389/fpsyt.2017.00285

47. Ciccarelli M, Griffiths MD, Nigro G, Cosenza M. Decision making, cognitive distortions and emotional distress: a comparison between pathological gamblers and healthy controls. J Behav Ther Exp Psychiatry. 2017;54:204-210. doi:10.1016/j.jbtep.2016.08.012

48. Balodis IM. Neuropsychology in GD: old and new directions. Curr Opin Behav Sci. 2020;31:48-53. doi:10.1016/j.cobeha.2019.11.002

49. MacLeod CM. The concept of inhibition in cognition. In: Gorfein DS, MacLeod CM, editors. Inhibition in Cognition. Washington, DC, US: American Psychological Association; 2007:3-23.

50. Ioannidis K, Hook R, Wickham K, Grant JE, Chamberlain SR. Impulsivity in gambling disorder and problem gambling: a meta-analysis. Neuropsychopharmacol. 2019;44(8):1354-1361. doi:10.1038/s41386-019-0393-9

51. Chowdhury NS. Pathological gambling and motor impulsivity: a systematic review with meta-analysis. J Gambl Stud. 2017;27.

52. Miyake A, Friedman NP. The nature and organization of individual differences in executive functions: four general conclusions. Curr Dir Psychol Sci. 2012;1:8-14.

53. Rochat L, Maurage P, Heeren A, Billieux J. Let's open the decisionmaking umbrella: a framework for conceptualizing and assessing features of impaired decision making in addiction. Neuropsychol Rev. 2019;29:27-51. doi:10.1007/s11065-018-9387-3

54. Hønsi A, Mentzoni RA, Molde H, Pallesen S. Attentional bias in problem gambling: a systematic review. J Gambl Stud. 2013;29 (3):359-375. doi:10.1007/s10899-012-9315-Z

55. Couture SM, Penn DL, Roberts DL. The functional Significance of social cognition in schizophrenia: a review. Schizophr Bull. 2006;32:20. doi:10.1093/schbul/sb1029
56. Adolphs R. The neurobiology of social cognition. Curr Opin Neurobiol. 2001;11:231-239. doi:10.1016/S0959-4388(00)00202-6

57. Green MF, Penn DL, Bentall R, et al. Social cognition in schizophrenia: an NIMH workshop on definitions, assessment, and research opportunities. Schizophr Bull. 2008;34:1211-1220. doi:10.1093/schbul/sbm 145

58. Hurel E, Challet-Bouju G, Bukowski N, Eyzop E, Grall-Bronnec M. Gambling and social cognition: a systematic review. Curr Addict Rep. 2019. doi:10.1007/s40429-019-00280-0

59. Challet-Bouju G, Bruneau M, Victorri-Vigneau C, Grall-Bronnec M. Cognitive remediation interventions for gambling disorder: a systematic review. Front Psychol. 2017;8. doi:10.3389/ fpsyg.2017.01961

60. Kornreich C, Saeremans M, Delwarte J, et al. Impaired non-verbal emotion processing in pathological gamblers. Psychiatry Res. 2016;236:125-129. doi:10.1016/j.psychres.2015.12.020

61. Argyriou E, Davison CB, Lee TTC. Response inhibition and internet gaming disorder: a meta-analysis. Addict Behav. 2017;7.

62. Choi S-W, Kim HS, Kim G-Y, et al. Similarities and differences among Internet gaming disorder, gambling disorder and alcohol use disorder: a focus on impulsivity and compulsivity. J Behav Addict. 2014;3:246-253. doi:10.1556/JBA.3.2014.4.6

63. Dong G, Potenza MN. Risk-taking and risky decision-making in Internet gaming disorder: implications regarding online gaming in the setting of negative consequences. $J$ Psychiatr Res. 2016;73:1-8. doi:10.1016/j.jpsychires.2015.11.011

64. Billieux J, Potenza MN, Maurage P, Brevers D, Brand M, King DL. Chapter 16 - Cognitive factors associated with gaming disorder. In: Verdejo-Garcia A, editor. Cognition and Addiction. Academic Press; 2020:221-230. doi:10.1016/B978-0-12-815298-0.00016-2

65. Schiebener J, Brand M. Decision-making and related processes in internet gaming disorder and other types of internet-use disorders. Curr Addict Rep. 2017;4(3):262-271. doi:10.1007/s40429-0170156-9

66. Metcalf O, Pammer K. Attentional bias in excessive massively multiplayer online role-playing gamers using a modified Stroop task. Comput Human Behav. 2011;27(5):1942-1947. doi:10.1016/ j.chb.2011.05.001

67. Peng X, Cui F, Wang T, Jiao C. Unconscious processing of facial expressions in individuals with internet gaming disorder. Front Psychol. 2017;8:1059. doi:10.3389/fpsyg.2017.01059

68. He J, Zheng Y, Fan L, Pan T, Nie Y. Automatic processing advantage of cartoon face in internet gaming disorder: evidence from P100, N170, P200, and MMN. Front Psychiatry. 2019;10:824. doi:10.3389/fpsyt.2019.00824

69. Su W, Potenza MN, Zhang Z, Hu X, Gao L, Wang Y. Do individuals with problematic and non-problematic internet game use differ in cooperative behaviors with partners of different social distances? Evidence from the prisoner's dilemma and chicken game. Comput Human Behav. 2018;87:363-370. doi:10.1016/j.chb.2018.05.040

70. Steward T, Mestre-Bach G, Vintró-Alcaraz C, et al. Food addiction and impaired executive functions in women with obesity. Eur Eat Disord Rev. 2018;26(6):574-584. doi:10.1002/erv.2636

71. Blume M, Schmidt R, Hilbert A. Executive functioning in obesity, food addiction, and binge-eating disorder. Nutrients. 2019;11:54. doi:10.3390/nu11010054

72. Wyckoff EP, Evans BC, Manasse SM, Butryn ML, Forman EM. Executive functioning and dietary intake: neurocognitive correlates of fruit, vegetable, and saturated fat intake in adults with obesity. Appetite. 2017;111:79-85. doi:10.1016/j.appet.2016.12.039

73. Brockmeyer T, Hamze Sinno M, Skunde M, et al. Inhibitory control and hedonic response towards food interactively predict success in a weight loss programme for adults with obesity. Obes Facts. 2016;9(5):299-309. doi:10.1159/000447492 
74. Córdova ME, Schiavon CC, Busnello FM, Reppold CT. Nutritional and neuropsychological profile of the executive functions on binge eating disorder in obese adults. Nutr Hosp. 2017;34: 1448-1454. doi:10.20960/nh.1151

75. Cassin SE, von Ranson KM. Is binge eating experienced as an addiction? Appetite. 2007;49: 687-690. doi:10.1016/j.appet.2007.06.012

76. Grubbs JB, Hoagland KC, Lee BN, Grant JT, Davison P, Reid $\mathrm{RC}$, et al. Sexual addiction 25 years on: A systematic and methodological review of empirical literature and an agenda for future research. Clinical Psychology Review. 2020;82: 101925. doi:10.1016/j.cpr.2020.101925

77. Mechelmans DJ, Irvine M, Banca P, et al. Enhanced attentional bias towards sexually explicit cues in individuals with and without compulsive sexual behaviours. PLoS One. 2014;9(8): e105476. doi:10.1371/journal.pone.0105476

78. Miner MH, Raymond N, Mueller BA, Lloyd M, Lim KO. Preliminary investigation of the impulsive and neuroanatomical characteristics of compulsive sexual behavior. Psychiatry Res. 2009;174(2):146-151. doi:10.1016/j.pscychresns.2009.04.008

79. Reid RC, Garos S, Carpenter BN, Coleman E. A surprising finding related to executive control in a patient sample of hypersexual men. $J \quad S e x \quad M e d . \quad 2011 ; 8(8): 2227-2236 . \quad$ doi:10.1111/j.17436109.2011.02314.x

80. Antons S, Brand M. Trait and state impulsivity in males with tendency towards Internet-pornography-use disorder. Addict Behav. 2018;79:171-177. doi:10.1016/j.addbeh.2017.12.029

81. Schiebener J, Laier C, Brand M. Getting stuck with pornography? Overuse or neglect of cybersex cues in a multitasking situation is related to symptoms of cybersex addiction. $J$ Behav Addict. 2015;4: 14-21. doi:10.1556/JBA.4.2015.1.5

82. Gerstein D, Hoffmann J, Larison C, Murphy S, Palmer A, Chuchro L, et al. Gambling Impact and Behavior Study. National Gambling Impact Study Commission (NORC);1999. Available: http://www.norc.org/PDFs/publications/ GIBSFinalReportApril1999.pdf.

83. Hodgins DC. Using the NORC DSM Screen for Gambling Problems as an outcome measure for pathological gambling: psychometric evaluation. Addictive Behaviors. 2004;29:16851690. doi:10.1016/j.addbeh.2004.03.017

84. Carnes PJ, Hopkins TA, Green BA Clinical relevance of the proposed sexual addiction diagnostic criteria: relation to the Sexual Addiction Screening Test-Revised. $J$ Addict Med. 2014;8:450-61. doi:10.1097/ADM.0000000000000080

85. Brunault P, Courtois R, Gearhardt A, Gaillard P, Journiac K, Cathelain $\mathrm{S}$, et al. Validation of the French Version of the DSM5 Yale Food Addiction Scale (YFAS 2.0) in a Nonclinical Sample. The Canadian Journal of Psychiatry. 2017;62:199-210. doi: $10.1177 / 0706743716673320$

86. Chan, A.-W., Tetzlaff, J. M., Altman, D. G., et al SPIRIT 2013 Statement: Defining Standard Protocol Items for Clinical Trials. Annals of Internal Medicine. 2013;158(3):200. doi:10.7326/00034819-158-3-201302050-00583

87. Chan, A.-W., Tetzlaff, J. M., Gøtzsche, P. C., et al SPIRIT 2013 explanation and elaboration: Guidance for protocols of clinical trials. BMJ. 2013;346. doi:10.1136/bmj.e7586

88. Zigmond AS, Snaith RP. The hospital anxiety and depression scale. Acta Psychiatr Scand. 198367:361-370.

89. Roberge P, Doré I, Menear M, et al. A psychometric evaluation of the French Canadian version of the Hospital Anxiety and Depression Scale in a large primary care population.Journal of Affective Disorders. 2013;147:171-179. doi:10.1016/j.jad.2012.10.029

90. Lecrubier Y, Sheehan D, Weiller E, Amorim P, Bonora I, Sheehan $\mathrm{KH}$, et al. The Mini International Neuropsychiatric Interview (MINI). A short diagnostic structured interview: reliability and validity according to the CIDI. Eur psychiatr. 1997;12:224-231. doi:10.1016/S0924-9338(97)83296-8
91. Chamberlain SR, Grant JE. Minnesota Impulse Disorders Interview (MIDI): Validation of a structured diagnostic clinical interview for impulse control disorders in an enriched community sample. Psychiatry Res 2018;265:279-283. doi:10.1016/j.psychres.2018.05.006

92. Ward MF, Wender PH, Reimherr FW The Wender Utah Rating Scale: an aid in the retrospective diagnosis of childhood attention deficit hyperactivity disorder. Am J Psychiatry. 1993;150:885890. doi:10.1176/ajp.150.6.885

93. Romo L, Legauffre C, Mille S, Chèze N, Fougères A-L, Marquez $\mathrm{S}$, et al. Propriétés psychométriques des versions françaises des échelles d'hyperactivité de Wender (WURS) et de l'Échelle de déficit d'attention de Brown (ADD). Encephale. 2010;36:380389. doi:10.1016/j.encep.2009.12.005

94. Kessler RC, Adler L, Ames M, Demler O, Faraone S, Hiripi E, et al. The World Health Organization Adult ADHD Self-Report Scale (ASRS): a short screening scale for use in the general population. Psychol Med. 2005;35:245-256. doi:10.1017/ s0033291704002892

95. van de Glind G, van den Brink W, Koeter MWJ, Carpentier P-J, van Emmerik-van Oortmerssen K, Kaye S, et al. Validity of the Adult ADHD Self-Report Scale (ASRS) as a screener for adult ADHD in treatment seeking substance use disorder patients. Drug Alcohol Depend. 2013;132:587-596. doi:10.1016/j.drugalcdep.2013.04.010

96. Ferris J, Wynne H. The Canadian Problem Gambling Index: Final Reports. 2001 p.59.

97. Demetrovics Z, Szeredi B, Rózsa S The three-factor model of Internet addiction: the development of the Problematic Internet Use Questionnaire. Behav Res Methods. 2008;40:563-574.

98. Laconi S, Urbán R, Kaliszewska-Czeremska K, Kuss DJ, Gnisci A, Sergi I, et al. Psychometric Evaluation of the Nine-Item Problematic Internet Use Questionnaire (PIUQ-9) in Nine European Samples of Internet Users. Front Psychiatry Psychon Bull Rev. 2019;10:136. doi:10.3389/fpsyt.2019.00136

99. Carnes P, Green B, Carnes S. The Same Yet Different: Refocusing the Sexual Addiction Screening Test (SAST) to Reflect Orientation and Gender. Sex Addict Compulsivity2010;17:7-30. doi:10.1080/10720161003604087

100. Hegbe KG, Courtois R, Brunault P, Reveillere C, Barrault S. Validation de la version française du Sexual Addiction Screening Test (SAST-Fr). [Validation of the French version of the Sexual Addiction Screening Test (SAST-Fr)]. Encephale. 2020;S0013700620300233. doi:10.1016/j.encep.2019.11.011

101. Garner D. Eating Disorder Inventory 2 - Professional manual. Psychological Assessment Ressources; 1991.

102. Tasca GA, Illing V, Lybanon-Daigle V, Bissada H, Balfour L. Psychometric Properties of the Eating Disorders Inventory-2 among Women Seeking Treatment for Binge Eating Disorder. Assessment. Psychiatry Res. 2003;10:228-236. doi:10.1177/1073191103255001

103. Whiteside SP, Lynam DR. The five factor model and impulsivity: Using a structural model of personality to understand impulsivity. Pers Individ Dif. Pers Individ Dif. 2001;30:669-689. doi:10.1016/ S0191-8869(00)00064-7

104. Van der Linden M, d'Acremont M, Zermatten A, Jermann F, Larøi F, Willems S, et al. A French Adaptation of the UPPS Impulsive Behavior Scale. Eur J Psychol Assess. 2006;22 (1):38-42. doi:10.1027/1015-5759.22.1.38

105. Rosenberg M. Society and the Adolescent Self-Image. Princeton University Press; 2015;

106. Vallieres EF, Vallerand RJ. Traduction et Validation CanadienneFrançaise de L'échelle de L'estime de Soi de Rosenberg. [Translation and Validation of the Canadian-French version of the Rosenberg SelfEsteem Scale]. International Journal of Psychology. 1990;25305-316 doi:10.1080/00207599008247865.

107. Cloninger CR, Svrakic DM, Przybeck TR. A psychobiological model of temperament and character. Arch Gen Psychiatry. 1993;50:975-990. doi:10.1001/archpsyc.1993.01820240059008 
108. Chakroun-Vinciguerra N, Faytout M, Pélissolo A, Swendsen J. Validation française de la version courte de l'Inventaire du Tempérament et du Caractére (TCI-125). [French validation of the short version of the Temperament and Character Inventory (TCI-125)]. J Behav Cogn Ther. Nat Protoc. 2005;15:27-33. doi:10.1016/S1155-1704(05)81209-1

109. Loas, G., Fremaux, D., \& Marchand, M. (1995). Etude de la structure factorielle et de la cohérence interne de la version française de l'échelle d'alexithymie de Toronto à 20 items (TAS20) chez un groupe de 183 sujets sains. Encéphale. 21:n²117-122.

110. Loas G, Otmani O, Verrier A, Fremaux D, Marchand MP. Factor analysis of the French version of the 20-Item Toronto Alexithymia Scale (TAS-20). Psychopathology. 1996;29:139-144. doi:10.2466/pms.1997.85.3.1018

111. Loas, G., Parker, J. D., Otmani, O., Verrier, A., \& Fremaux, D. (1997). Confirmatory factor analysis of the French translation of the 20-item Toronto Alexithymia Scale. Perceptual and Motor Skills. 85;(3pt 1):1018. doi:10.2466/pms.1997.85.3.1018

112. Martinez ME. What is Metacognition?Phi Delta Kappan. 2006;87 (9):696-699. doi:10.1177/003172170608700916

113. Spada MM, Caselli G, Nikčević AV, Wells A. Metacognition in addictive behaviors. Addictive Behaviors. 2015;44:9-15. doi:10.1016/j.addbeh.2014.08.002

114. Quiles C, Verdoux H, Prouteau A. Assessing metacognition during a cognitive task: impact of "on-line" metacognitive questions on neuropsychological performances in a non-clinical sample. $J$ Int Neuropsychol Soc. 2014;20(5):547-554. doi:10.1017/ S1355617714000290

115. Spada MM, Wells A. Metacognitive beliefs about alcohol use: development and validation of two self-report scales. Addict Behav. 2008;33(4):515-527. doi:10.1016/j.addbeh.2007.10.011

116. Brickenkamp R. D2. Test d'attention concentrée manuel. Hogrefe; 2007;

117. Hester R, Dixon V, Garavan H. A consistent attentional bias for drug-related material in active cocaine users across word and picture versions of the emotional Stroop task. Drug Alcohol Depend. 2006;81:251-257. doi:10.1016/j.drugalcdep.2005.07.002

118. Boyer M, Dickerson M. Attentional bias and addictive behaviour: automaticity in a gambling-specific modified Stroop task. Addiction. 2003;98:61-70. doi:10.1046/j.1360-0443.2003.00219.x

119. Pilli R, Naidu M, Pingali UR, Shobha JC, Reddy AP. A computerized stroop test for the evaluation of psychotropic drugs in healthy participants. Indian $J$ Psychol Med. 2013;35 (2);180-189. doi:10.4103/0253-7176.116251

120. Penner I-K, Kobel M, Stöcklin M, Weber P, Opwis K, Calabrese $\mathrm{P}$. The stroop task: comparison between the original paradigm and computerized versions in children and adults. Clin Neuropsychol. 2012;1-12. doi:10.1080/13854046.2012.713513

121. Stroop JR. Studies of interference in serial verbal reactions. Journal of Experimental Psychology. 1935;18:643-662. doi:10.1037/h0054651

122. Trotzke P, Starcke K, Pedersen A, Brand M Cue-induced Craving in Pathological Buying: Empirical Evidence and Clinical Implications. Psychosomatic Medicine. 2014;76:694-700. doi:10.1097/PSY.0000000000000126

123. van Rooijen R, Ploeger A, Kret ME. The dot-probe task to measure emotional attention: A suitable measure in comparative studies? Psychon Bull Rev. 2017;24: 1686-1717. doi:10.3758/ s13423-016-1224-1

124. Damasio AR. Descarte's error: emotion, reason, and the human brain /. G.P. Putnam; 1994.

125. Kovács I, Richman MJ, Janka Z, Maraz A, Andó B. Decision making measured by the Iowa Gambling Task in alcohol use disorder and gambling disorder: a systematic review and metaanalysis. Drug Alcohol Depend. 2017;181:152-161. doi:10.1016/ j.drugalcdep.2017.09.023
126 Franken IHA, van Strien JW, Nijs I, Muris P. Impulsivity is associated with behavioral decision-making deficits. Psychiatry Research. 2008;158:155-163. doi:10.1016/j.psychres.2007.06.002

127. Bechara A, Damasio AR, Damasio H, Anderson S. Insensitivity to future consequences following damage to human prefrontal cortex. Cognition. 1994;50:9. doi:10.1016/ 0010-0277(94)90018-3

128. Goudriaan AE, Oosterlaan J, De Beurs E, Van den Brink W. Decision making in pathological gambling: A comparison between pathological gamblers, alcohol dependents, persons with Tourette syndrome, and normal controls. Cognitive Brain Research. 2005;23:137-151. doi:10.1016/j.cogbrainres.2005.01.017

129. Cardebat D, Doyon B, Puel M, Goulet P, Joanette Y. [Formal and semantic lexical evocation in normal subjects. Performance and dynamics of production as a function of sex, age and educational level]. Acta Neurol Belg. 1990;90:207-217.

130. Lezak MD, Howieson DB, Loring DW, Hannay HJ, Fischer JS. Neuropsychological assessment, 4th ed. New York, NY, US: Oxford University Press; 2004.

131. Eslinger PJ, Grattan LM. Frontal lobe and frontal-striatal substrates for different forms of human cognitive flexibility. Neuropsychologia. 1993;31:17-28. doi:10.1016/0028-3932(93)90077-D

132. Bowie CR, Harvey PD. Administration and interpretation of the Trail Making Test. Nat Protoc. 2006;1:2277-2281. doi:10.1038/ nprot.2006.390

133. Nelson HE. A Modified Card Sorting Test Sensitive to Frontal Lobe Defects. Cortex. 1976;12:313-324. doi:10.1016/S00109452(76)80035-4

134. Mackinnon A, Mulligan R. Estimation de l'intelligence prémorbide chez les francophones. Encephale. 2005;31:31-43. doi:10.1016/S00137006(05)82370-X

135. Bright $\mathrm{P}$, Hale E, Gooch VJ, Myhill T, van der Linde I. The National Adult Reading Test: restandardisation against the Wechsler Adult Intelligence Scale-Fourth edition. Neuropsychol Rehabil. 2016;28: 11. doi:10.1080/09602011.2016.1231121

136. Rey A. L'examen psychologie dan les cas d'encéphalopathie traumatique (Les problèmes) [The psychological examination in cases of traumatic encepholopathy (Problems)]. Arch Psychol. 1941;28:215-285.

137. Meyer, J. E., \& Meyer, K. R. (1996). Rey complex figure test and recognition trial: Professional manual. (Par.).

138. Rey A. Test de Copie et de Reproduction de Mémoire de Figures Géométriques Complexes. [Test of copy and Reproduction of Memory of Complex Geometric Figures]. Paris: Editions du centre de psychologie appliquée; 1959.

139. Bishop DVM, Aamodt-Leeper G, Creswell C, McGurk R, Skuse DH. Individual differences in cognitive planning on the Tower of Hanoi Task: neuropsychological maturity or measurement error? J Child Psychol Psychiatry. 2001;42:551-556. doi:10.1017/S0021963001007247

140. Terriot K, Mezza J. WAIS IV: proposition d'une méthodologie d'interprétation. [WAIS IV: proposal for an interpretation methodology]. L'orientation scolaire et professionnelle. 2014;(43/2). doi:10.4000/osp. 4379

141. Miyake A, Friedman NP, Emerson MJ, Witzki AH, Howerter A, Wager T. The unity and diversity of executive functions and their contributions to complex "Frontal lobe" tasks: a latent variable analysis. Cogn Psychol. 2000;41:49-100. doi:10.1006/ cogp.1999.0734

142. Schulz K, Fan J, Magidina O, Marks D, Hahn B, Halperin J. Does the emotional go/no-go task really measure behavioral inhibition? Convergence with measures on a non-emotional analog. Arch Clin Neuropsychol. 2007;22(2):151-160. doi:10.1016/j.acn.2006.12.001

143. van Holst RJ, van Holstein M, van den Brink W, Veltman DJ, Goudriaan AE. Response inhibition during cue reactivity in problem gamblers: an fMRI Study. PLoS One. 2012;7:e30909. doi:10.1371/journal.pone.0030909 
144. Dougherty DM, Marsh-Richard DM, Hatzis ES, Nouvion SO, Mathias CW. A test of alcohol dose effects on multiple behavioral measures of impulsivity. Drug Alcohol Depend. 2008;96:18. doi:10.1016/j.drugalcdep.2008.02.002

145. Bertoux M, Delavest M, de Souza LC, et al. Social cognition and emotional assessment differentiates frontotemporal dementia from depression. J Neurol Neurosurg Psychiatry. 2012;83 (4):411-416. doi:10.1136/jnnp-2011-301849

146. Lorains FK, Stout JC, Bradshaw JL, Dowling NA, Enticott PG. Self-reported impulsivity and inhibitory control in problem gamblers. $J$ Clin Exp Neuropsychol. 2014;36(2):144-157. doi:10.1080/13803395.2013.873773

147. Petry NM, Zajac K, Ginley MK. Behavioral addictions as mental disorders: to be or not to be? Annu Rev Clin Psychol. 2018;14:399-423. doi:10.1146/annurev-clinpsy-032816-045120

148. Karim R, Chaudhri P. Behavioral addictions: an overview. J Psychoactive Drugs. 2012;44:5-17. doi:10.1080/ 02791072.2012 .662859

149. Albein-Urios N, Martinez-González JM, Lozano Ó, Clark L, Verdejo-García A. Comparison of impulsivity and working memory in cocaine addiction and pathological gambling: implications for cocaine-induced neurotoxicity. Drug Alcohol Depend. 2012;126:1-6. doi:10.1016/j.drugalcdep.2012.03.008

150. Di Nicola M, Tedeschi D, De Risio L, et al. Co-occurrence of alcohol use disorder and behavioral addictions: relevance of impulsivity and craving. Drug Alcohol Depend. 2015;148:118-125. doi:10.1016/j.drugalcdep.2014.12.028

151. Marazziti D, Presta S, Baroni S, Silvestri S, Dell'Osso L. Behavioral addictions: a novel challenge for psychopharmacology. CNS Spectr. 2014;19(6):486-495. doi:10.1017/S1092852913001041

152. Olsen CM. Natural rewards, neuroplasticity, and non-drug addictions. Neuropharmacology. 2011;61:1109-1122. doi:10.1016/ j.neuropharm.2011.03.010

153. Aboujaoude E, Salame WO. Naltrexone: a pan-addiction treatment? CNS Drugs. 2016;30(8):719-733. doi:10.1007/ s40263-016-0373-0

154. Mouaffak F, Leite C, Hamzaoui S, Benyamina A, Laqueille X, Kebir O. Naltrexone in the treatment of broadly defined behavioral addictions: a review and Meta-Analysis of Randomized Controlled Trials. EAR. 2017;23:204-210. doi:10.1159/000480539

155. Kraus SW, Etuk R, Potenza MN. Current pharmacotherapy for gambling disorder: a systematic review. Expert Opin Pharmacother. 2020;21(3):287-296. doi:10.1080/14656566.2019.1702969

156. Rass O, Schacht RL, Buckheit K, Johnson MW, Strain EC, Mintzer MZ. A randomized controlled trial of the effects of working memory training in methadone maintenance patients. Drug Alcohol Depend. 2015;156:38-46. doi:10.1016/j. drugalcdep.2015.08.012

157. Bell MD, Vissicchio NA, Weinstein AJ. Cognitive training and work therapy for the treatment of verbal learning and memory deficits in veterans with alcohol use disorders. J Dual Diagn. 2016;12(1):83-89. doi:10.1080/15504263.2016.1145779
158. Gladwin TE, Wiers CE, Wiers W. Cognitive neuroscience of cognitive retraining for addiction medicine: from mediating mechanisms to questions of efficacy. Prog Brain Res. 2016;224:323-344. doi:10.1016/bs.pbr.2015.07.021

159. Manning V, Verdejo-Garcia A, Lubman DI. Neurocognitive impairment in addiction and opportunities for intervention. Curr Opin Behav Sci. 2017;13:40-45. doi:10.1016/j.cobeha.2016.10.003

160. Luquiens A, Miranda R, Benyamina A, Carré A, Aubin H-J. Cognitive training: a new avenue in gambling disorder management? Neurosci Biobehav Rev. 2019;106:227-233. doi:10.1016/j.neubiorev.2018.10.011

161. Rabinovitz S, Nagar M. Possible end to an endless quest? Cognitive bias modification for excessive multiplayer online gamers. Cyberpsychol Behav Soc Netw. 2015;18(10):581-587. doi:10.1089/cyber.2015.0173

162. Stevens L, Verdejo-García A, Goudriaan AE, Roeyers H, Dom G, Vanderplasschen W. Impulsivity as a vulnerability factor for poor addiction treatment outcomes: a review of neurocognitive findings among individuals with substance use disorders. $J$ Subst Abuse Treat. 2014;47(1):58-72. doi:10.1016/j.jsat.2014.01.008

163. Lim J-A, Lee J-Y, Jung HY, et al. Changes of quality of life and cognitive function in individuals with Internet gaming disorder: a 6-month follow-up. Medicine (Baltimore). 2016;95(50):e5695. doi:10.1097/MD.0000000000005695

164. Hudson A, Olatunji BO, Gough K, Yi S, Stewart SH. Eye on the Prize: High-Risk Gamblers Show Sustained Selective Attention to Gambling Cues. J Gambl Issues. 2016;34: 20. doi:10.4309/ jgi.2016.34.6

165. Tan JW, Walter S, Scheck A, et al. Repeatability of facial electromyography (EMG) activity over corrugator supercilii and zygomaticus major on differentiat-ing various emotions $J$ Ambient Intell Human Comput. 2011;9: 243-260. doi:10.1007/s12652011-0084-9

166. Robbins S, Ehrman R. The role of attentional bias in substance abuse. Behav Cogn Neurosci Rev. 2005;3: 243-260. doi:10.1177/ 1534582305275423

167. Dresler T, Mériau K, Heekeren HR, van der Meer E. Emotional Stroop task: effect of word arousal and subject anxiety on emotional interference Psychol Res. 2009;73: 364-371. doi:10.1007/ s00426-008-0154-6

168. Brown MRG, Benoit JRA, Juhás M, et al. Neural correlates of high-risk behavior tendencies and impulsivity in an emotional Go/NoGo fMRI task. Front Syst Neurosci. 2015;9:(24). doi:10.3389/fnsys.2015.00024
Neuropsychiatric Disease and Treatment

\section{Publish your work in this journal}

Neuropsychiatric Disease and Treatment is an international, peerreviewed journal of clinical therapeutics and pharmacology focusing on concise rapid reporting of clinical or pre-clinical studies on a range of neuropsychiatric and neurological disorders. This journal is indexed on PubMed Central, the 'PsycINFO' database and CAS, and is the official journal of The International Neuropsychiatric Association (INA). The manuscript management system is completely online and includes a very quick and fair peer-review system which is all easy to use. Visit http://www.dovepress.com/testimonials.php to read real quotes from published authors. 